\title{
Low Pass Filter Design With Artificial Ground Structure
}

\author{
Wahyu Hendra Gunawan ${ }^{1^{*}}$, Fitri Oktafiani ${ }^{2}$, Bambang Sugeng ${ }^{3}$, Lukman $^{4}$ \\ ${ }^{1,2,3,4}$ Department of Instrumentation and Electronic, STTMigas Balikpapan \\ *e-mail: wahyuhendrag@gmail.com
}

\begin{abstract}
In this paper, low pass band filter with via holes and using artificial ground structure are proposed. The design contains a u-shaped parasite element and gives via hole which is connected to the ground on the adjacent side with a copper. A hole in this design has a diameter $1 \mathrm{~mm}$. The A have the form square $15 \mathrm{~mm} x 17.5 \mathrm{~mm}$, given an effect, if compared with the non-artificial ground structure system, this addition show that the bandwidth of the low pass filter is shifting regarding this condition with value 400Mhz at frequency 1 GHz.On this paper, the low pass filter also gives the pass band filter on frequency $3.2 \mathrm{GHz}$ which is constructed by the artificial ground structure. The simulation results with this design are simulated by computer based on finite integration method and show a good agreement and can be performed for a low pass band filter applications in the future.
\end{abstract}

Keywords: low pass filter, less via, artificial ground structure

\section{Introduction}

Lately, microstrip low pass filter (LPF) is very popular among researcher and its growth to make a simple, compact and inexpensive. Planar LPF's are particularly popular design because they can be measured using printed circuit technology and appropriate to use for commercial need. Various approaches have been reported in the literature to achieve a wide stop band region on low pass filters. One of the feature low pass filters is to reject low frequency that can interfere the system, so only selected frequency can break out from the system. Open stubs on low pass filter are designed to distribute and generated frequency on that system. Different stub sizes on one system are possible and every each stub represents one resonant [1].

In this paper, low pass filter using open stubs along the transmission line to get the resonant effect on the system, because of this system has wide stop band. Added an element u-shaped on design, can give the advantage and disadvantage, it lowers the performance of the filter because the power is divided into the addition element but it will give a wide band stop to the filter as the advantage. The artificial ground structure (AGS) are proposed in many research areas, this not a new topic but applying on filter design it still new. AGS in this filter is proposed with a square shape and arrays [2].

\section{Methods}

The design of low pass filter with $1 \mathrm{GHz}$ cutoff frequency is designed using three sectional stubs putting along the transmission line, with a u-shaped element which is connected to the ground using fewer vias. On Figure 1 is the proposed low-pass filter which is connected with two connectors $50 \mathrm{Ohm}$ that installed on the edge of the line. The line and are adjusted to be matched with $50 \mathrm{Ohm}$ and the stubs are design to getting a various effect from the low-pass filter [3], [4].

On Figure 1a there are two open stub sizes, the stub synthesizes in this filter are based on a left-hand circuit design that Kuroda identities well explained.

$Z_{\text {in }}=j Z_{1} \tan \beta l$ 




a. Top view of low pass filter

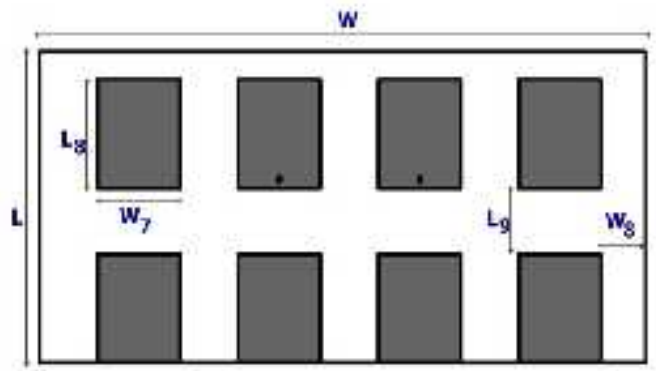

b. Bottom view of low pass filter

Figure 1. Geometry of the proposed filter

Where $Z_{i n}$ is the load of the circuit that calculates from a load of the stub and $Z_{\text {in }}$ is unnormalized value because of the $Z_{1}$ in equation 1, Cascading $A B C D$ matrices for this circuit is:

$$
\begin{aligned}
& {\left[\begin{array}{ll}
A & B \\
C & D
\end{array}\right]_{L H S}=\left[\begin{array}{cc}
1 & j Z_{1} \tan \beta l \\
0 & 1
\end{array}\right] \cdot\left[\begin{array}{cc}
1 & j Z_{2} \tan \beta l \\
\frac{j \tan \beta l}{Z_{2}} & 1
\end{array}\right] \frac{1}{\sqrt{1+\tan \beta l^{2}}}} \\
& =\frac{1}{\sqrt{1+\tan \beta l^{2}}}\left[\begin{array}{cc}
1-\tan \beta l^{2} \frac{Z_{1}}{Z_{2}} & j Z_{2} \tan \beta l+j Z_{1} \tan \beta l \\
\frac{j \tan \beta l}{Z_{2}} & 1
\end{array}\right]
\end{aligned}
$$

The smallest one has a high impedance which is useful to provide cutoff frequency and attenuation pole with some frequency. On Figure $1 \mathrm{~b}$ we can see the AGS are installed on the adjacent side which is set by the array[5], [6]. This low pass filter design used FR-4 as a substrate with permittivity 4.3 and the compact size of the filter is $1.6 \mathrm{~mm} \times 110 \mathrm{~mm} \times 45 \mathrm{~mm}$. All filter parameters are optimized by particle swarm optimization that includes in CST Microwave Studio.

\section{Results}

The design procedure on this filter is based on transforming the circuit with the Kuroda identities, in order to obtain an equivalent circuit with only series inductance and transmission lines with different impedance and stubs. These low pass filter designs have a cut-off frequency 1.4 fo until 3.6 fo have a ripple $0.5 \mathrm{~dB}$ in the pass band.
Figure 2 shows the magnitude $|\mathrm{S} 11|$ and $|\mathrm{S} 21|$ over frequency. All the distance is fixed by the cut-off frequency of the filter, $1.4 \mathrm{GHz}$. Because of the initial symmetry of the coefficients, the final design is also symmetric.

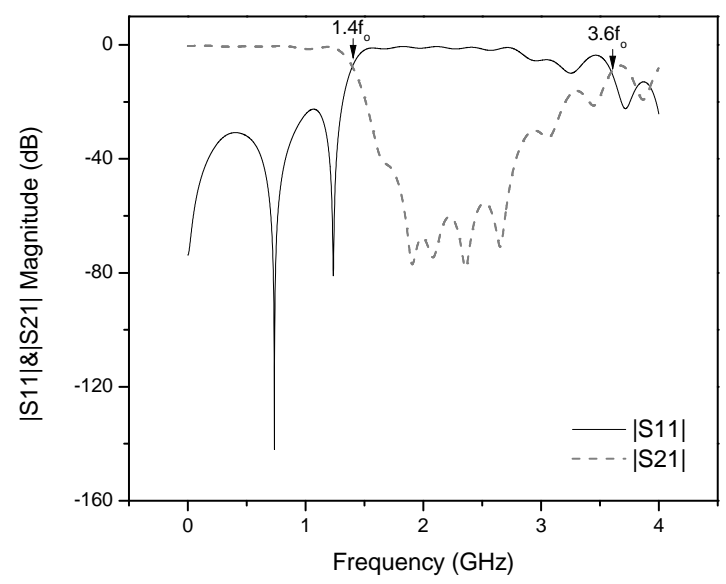

Figure 2. Result of the proposed low pass filter

As we can see on the Fig. 3 the red line is a magnitude of the reflective signal that generated from the filter with no AGS on the adjacent side. Adding an AGS structure in the adjacent side give an enhancement of the bandwidth of the filter which is shown on the blue line in Figure 3.The bandwidth increased after AGS added on the structure is $300 \mathrm{MHz}$ on the lower frequency. The higher frequency after AGS added is more than $4 \mathrm{GHz}$ as can we seen on Figure 3. The reflection magnitude |S21| got lower on the frequency $3.2 \mathrm{GHz}$ but still lower than $-10 \mathrm{~dB}$. 


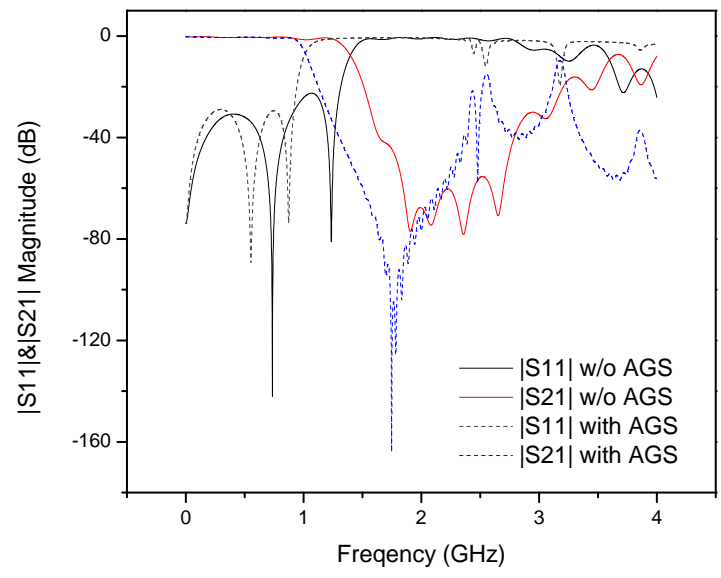

Figure 3. Comparison result of low pass filter with and without AGS

\section{Conclusions}

Design of low pass filter with stub and less via is proposed and analyzed in detail. This design is modified from the original design of Kuroda identities. The structure is connected with the artificial ground structure with less via. The open stubs in this design also give an enhancement in bandwidth.

\section{Acknowledgement}

I would like thank to Yono Hadi Pramono for their dedication to author and preparation this paper. Further research in this paper will need comparison data between measurement and simulation.

\section{References}

[1] S. Khalid, P. W. Wong, and L. Y. Cheong, "A Novel Synthesis Procedure for Ultra Wideband (UWB) Bandpass Filters," Progress In Electromagnetics Research, vol. 141, pp. 249-266, 2013.

[2] F. Benriad, "A Novel Microstrip Low Pass Filter Based on Ring Topology," International Journal of Microwave and Optical Technology, vol. 12, Jan. 2017.

[3] F. Wang and N. Yu, "An UltracompactButterworth Low-Pass Filter Based on Coaxial Through-Silicon Vias," IEEE Transactions on Very Large Scale Integration (VLSI) Systems, vol. 25, no. 3, pp. 1164-1167, Mar. 2017.
[4] H. Peng, J. Zhao, and B. Wang, "Compact Microstrip UWB Bandpass Filter with TripleNotched Bands and Wide Upper Stopband," Progress In Electromagnetics Research, vol. 144, pp. 185-191, 2014.

[5] J. Chen, Z.-B.Weng, Y.-C.Jiao, and F.-S. Zhang, "Lowpass Filter Design of Hilbert Curve Ring Defected Ground Structure," Progress In Electromagnetics Research, vol. 70, pp. 269-280, 2007.

[6] K. Xu, Y. Zhang, D. Li, Y. Fan, J. L.-W. Li, W. T. Joines, and Q. H. Liu, "Novel Design of a Compact Triple-Band Bandpass Filter Using Short Stub-Loaded Sirs and Embedded Sirs Structure," Progress In Electromagnetics Research, vol. 142, pp. 309-320, 2013. 